\title{
Role of platelet indices in prediction of preeclampsia
}

\author{
Muzaffer Temur ${ }^{1}\left(\mathbb{D}\right.$, Fatma Nurgül Taşgöz $^{2} \oplus$, Tayfur Çift $^{2}{ }^{\circledR}$, \\ Gülç̧in Serpim³ ${ }^{3}$, Emin Üstünyurt ${ }^{2} \mathbb{D}$ \\ ${ }^{1}$ Bursa Yıldırım Special Doruk Hospital, Bursa Turkey \\ ${ }^{2}$ HSU Bursa Yüksek Ihtisas Training and Research Hospital, Bursa Yüksek Ihtisas Eğitim ve Araştırma \\ Hastanesi Mimar Sina Mah Emniyet Cad Yıldırım, Bursa, Turkey \\ ${ }^{3}$ Yozgat City Hospital Department of Obstetrics and Gynecology, Yozgat, Turkey
}

\begin{abstract}
Objectives: To compare platelet indices in preeclamptic and normotensive pregnants and to investigate the clinical use of these parameters in preeclampsia prediction.

Material and methods: This retrospective case- control study included 257 preeclampsia patients and 264 healthy pregnant women as the control group. The groups were compared in terms of platelet count (PC), mean platelet volume (MPV), platelet distribution range (PDW), plateletcrit (Pct), Pct / MPV ratio and PC / MPV ratio.

Results: Between the preeclampsia group and the control group; mean platelet count ( $227.22 \pm 78.58$ vs $236.69 \pm 64.30$ ), plateletcrit (PCT) ( $0.21 \pm 0.06$ vs $0.24 \pm 0.27)$, and platelet distribution width (PDW) (17.11 \pm 0.80 vs $17.29 \pm 0.82)$ were not significantly different $(p>0.05)$. However, MPV values were significantly higher in the preclampsia group compared to the control group $(9.66 \pm 1.62$ and $8.92 \pm 1.33$, respectively) $(p<0.001)$. In our study, the optimum cut-off value of MPV was 9.15 with $58.7 \%$ sensitivity and $61.7 \%$ specificity for the prediction of preeclampsia. Pct/MPV ratio $(0.02 \pm 0.007$ vs $0.027 \pm 0.029)(p=0.01)$ and PC/MPV ratio ( $24.63 \pm 10.90$ vs $27.63 \pm 10.24)(p=0.001)$ were significantly lower in the preeclampsia group than in the control group.

Conslusions: In preeclampsia, changes in platelet functions, destruction and production lead to changes in platelet indices. Compared with normal healthy pregnant women, preeclamptic pregnant women have higher MPV values. In preeclampsia prediction, MPV and PC/MPV ratio are promising as a diagnostic parameter.
\end{abstract}

Key words: mean platelet volume; platelet count; preeclampsia

Ginekologia Polska 2021; 92, 11: 792-796

\section{INTRODUCTION}

Preeclampsia is a multifactorial and multisystemic disease characterized by high blood pressure and proteinuria after 20 weeks of gestation. Preeclampsia, which has an important role in maternal morbidity and mortality, differs geographically and affects $5-8 \%$ of all pregnancies [1, 2]. Although its pathophysiology is still unclear, hemostatic changes such as endothelial cell damage, platelet activation, increased intravascular thrombin formation have been known to be the main events in the pathophysiology of preeclampsia [3].

In normal pregnancy, a small increase in platelet aggregation is observed, which is compensated by increased platelet synthesis. Mean platelet volume (MPV) also increases due to increased platelet synthesis [4,5]. Preeclampsia which is characterized by endothelial damage; uncontrolled intra- vascular platelet activation and increased platelet destruction are expected outcome [6]. Decrease in platelet count stimulates new platelet synthesis in the bone marrow and releases young and large platelets into the circulation [7].

The role of platelets in the pathophysiology of preeclampsia and therefore MPV values may vary in preeclampsia. The aim of this study was to evaluate whether MPV and PC/MPV ratio, which can be detected in a simple whole blood count, have a place in clinical practice in predicting preeclampsia.

\section{MATERIAL AND METHODS}

This retrospective study included 521 patients admitted to the Gynecology and Obstetrics Clinic of our hospital between 2018 and 2019, a tertiary center with 12000 deliveries annualy. The study complies with the Declaration of

HSU Bursa Yüksek İhtisas Training and Research Hospital, Bursa Yüksek Ihtisas Eğitim ve Araştırma Hastanesi Mimar Sina Mah Emniyet Cad Yıldırım, 16310 Bursa, Turkey e-mail: tayfur_cift@yahoo.com 
Helsinki. This study was approved by Bursa Yuksek Ihtisas Ethics Committee (2011-KAEK-25 2020/02-18). In our institute, which is a training and research hospital, a general informed consent from patient admission is used in retrospective studies. The patients were divided into two groups as 264 healthy normotensive pregnant women and 257 preeclampsia patients with no medical or obstetric problems other than preeclampsia. Preeclampsia was diagnosed according to the American College of Obstetricians and Gynecologists (ACOG) Practice Bulletin [8]. In a patient whose blood pressure was normal previously; systolic blood pressure $>140 \mathrm{mmHg}$, diastolic blood pressure $>90 \mathrm{mmHg}$ in two separate measurements made at least six hours and marked proteinuria (urinary protein excretion $>300 \mathrm{mg} / 24 \mathrm{~h}$ ), after $20^{\text {th }}$ gestational week were diagnostic criteria.

Women with systemic disease (hypertension, endocrinological pathology, diabetes mellitus, heart disease, renal disease, liver disease), gestational diabetes mellitus, morbid obesity (BMI $\geq 40 \mathrm{~kg} / \mathrm{m}^{2}$ ), history of thromboembolism or known thrombophilic disease, anticoagulant use, malformed fetus and multiple pregnancies, 'hemolysis, increased liver function enzymes and low platelet count' (HELLP) syndrome were excluded from the study.

\section{Statistical Analysis}

In the descriptive statistics of the data; mean, standard deviation, median, min-max, ratio and frequency values were used. The distribution of the variables was checked by Kolmogorov-Simirnov test. Independent sample t-test (two-tailed) was used for data analysis. Statistical significance was defined as $p<0.05$.

\section{RESULTS}

Table 1 presents the maternal demographic characteristics and delivery outcomes of both groups. The ages of the patients in the preeclampsia group (33.02 \pm 5.82 / $/ 26.77 \pm 6.09 ; \mathrm{p}<0.001)$ and body mass index (BMI) $(33.02 \pm 5.82 / 29.75 \pm 4.92 ; p<0.001)$ were significantly higher than the control group. While there was no significant difference between gravida and parity numbers, the gestational week at birth $(34.81 \pm 3.76 / 38.36), 99 ; p<0.001)$, birth weight of infants $(2464 \pm 947 / 3229 \pm 573 ; p<0.001)$ and $1^{\text {st }}$ minute $(8.35 \pm 1.63 / 8.82 \pm 0.84 ; \mathrm{p}<0.001)$ and $5^{\text {th }}$ minute $(9.28 \pm 1.67 / 9.75 \pm 0.82 ; p<0.001)$ APGAR scores were significantly lower in the preeclampsia group than in the control group.

Table 2 contains laboratory data containing the platelet indices in detail. When the groups were evaluated in terms of whole blood count parameters; white blood cell (WBC), hemoglobin (hb), hematocrit (hct), platelet count (PC), platelet distribution range (PDW), plateletcrit (Pct)
Table 1. Basic demographic and clinical datas

\begin{tabular}{|c|c|c|c|}
\hline & $\begin{array}{l}\text { Control } \\
\mathrm{n}: 257\end{array}$ & $\begin{array}{l}\text { Preeclampsia } \\
\text { n: } 264\end{array}$ & $\mathbf{p}$ \\
\hline Age & $26.77 \pm 6.09$ & $30.23 \pm 6.52$ & $<0.001$ \\
\hline $\mathrm{BMI}^{*}$ & $29.75 \pm 4.92$ & $33.02 \pm 5.82$ & $<0.001$ \\
\hline Gravidas & $2.39 \pm 1.50$ & $2.58 \pm 1.59$ & 0.162 \\
\hline Parity & $1.09 \pm 1.2$ & $1.13 \pm 1.24$ & 0.690 \\
\hline Gestastional age & $38.36 \pm 1.99$ & $34.81 \pm 3.76$ & $<0.001$ \\
\hline Birth weigth & $3229 \pm 573$ & $2464 \pm 947$ & $<0.001$ \\
\hline Fetal length & $50.05 \pm 2.60$ & $46.04 \pm 5.89$ & $<0.001$ \\
\hline Fetal head circumference & $34.53 \pm 1.68$ & $32.41 \pm 3.47$ & $<0.001$ \\
\hline Cyistolic blood pressure & $108.02 \pm 12.13$ & $155.76 \pm 13.98$ & $<0.001$ \\
\hline Diastolic blood pressure & $64.90 \pm 9.27$ & $98.39 \pm 9.34$ & $<0.001$ \\
\hline APGAR $1^{\text {th }}$ minute & $8.82 \pm 0.84$ & $8.35 \pm 1.63$ & $<0.001$ \\
\hline APGA $5^{\text {th }}$ minute & $9.75 \pm 0.82$ & $9.28 \pm 1.67$ & $<0.001$ \\
\hline
\end{tabular}

*BMI- Body Mass Index

Table 2. Comparison of laboratory parameters between groups

\begin{tabular}{|c|c|c|c|}
\hline & $\begin{array}{l}\text { Control } \\
\mathrm{n}: 257\end{array}$ & $\begin{array}{l}\text { Preeclampsia } \\
\text { n: } 264\end{array}$ & $p$ \\
\hline $\begin{array}{l}\text { Blood urea nitrogen } \\
(\mathrm{mg} / \mathrm{dL})\end{array}$ & $7.92 \pm 2.38$ & $11.28 \pm 5.04$ & $<0.001$ \\
\hline Creatinine $(\mathrm{mg} / \mathrm{dL})$ & $0.66 \pm 0.33$ & $0.76 \pm 0.24$ & $<0.001$ \\
\hline $\begin{array}{l}\text { Aspartate } \\
\text { aminotransferase (AST) } \\
\text { (U/L) }\end{array}$ & $20.43 \pm 6.40$ & $33.61 \pm 40.96$ & $<0.001$ \\
\hline $\begin{array}{l}\text { Alanine } \\
\text { Aminotransferase (ALT) } \\
(\mathrm{U} / \mathrm{L})\end{array}$ & $11.19 \pm 5.78$ & $24.97 \pm 39.00$ & $<0.001$ \\
\hline $\begin{array}{l}\text { White blood cel I (WBC) } \\
(\mathrm{mcL})\end{array}$ & $10.82 \pm 2.94$ & $11.21 \pm 3.30$ & 0.155 \\
\hline $\begin{array}{l}\text { Hemoglobine ( } \mathrm{Hb}) \\
(\mathrm{g} / \mathrm{dL})\end{array}$ & $11.46 \pm 1.27$ & $11.70 \pm 1.44$ & 0.045 \\
\hline Hematocrite (Htc) $(\%)$ & $34.98 \pm 3.36$ & $35.35 \pm 4.01$ & 0.257 \\
\hline Platelets (PLT) (mcL) & $236.69 \pm 64.30$ & $227.22 \pm 78.58$ & 0.133 \\
\hline Plateletcrite (PCT) (\%) & $0.24 \pm 0.27$ & $0.21 \pm 0.06$ & 0.093 \\
\hline $\begin{array}{l}\text { Red cell distribution } \\
\text { width (RDW) (\%) }\end{array}$ & $15.36 \pm 2.50$ & $15.42 \pm 2.70$ & 0.813 \\
\hline $\begin{array}{l}\text { Platelet distribution } \\
\text { width (PDW) (\%) }\end{array}$ & $17.29 \pm 0.82$ & $17.11 \pm 0.80$ & 0.014 \\
\hline $\begin{array}{l}\text { Mean platelet volume } \\
\text { (MPV) (fL) }\end{array}$ & $8.92 \pm 1.33$ & $9.66 \pm 1.62$ & $<0.001$ \\
\hline $\begin{array}{l}\text { Mean cell volume } \\
\text { (MCV) (fL) }\end{array}$ & $83.53 \pm 7.16$ & $83.82 \pm 7.35$ & 0.651 \\
\hline PLT/MPV & $27.63 \pm 10.24$ & $24.63 \pm 10.90$ & 0.001 \\
\hline PCT/MPV & $0.027 \pm 0.029$ & $0.02 \pm 0.007$ & 0.01 \\
\hline
\end{tabular}

values were not significantly different; only mean platelet volume (MPV) values were significantly higher in the preeclampsia group $(9.66 \pm 1.62 / 8.92 \pm 1.33 ; p<0.001)$. 
Also in the preeclampsia group; the Pct/MPV ratio $(0.02 \pm 0.007$ vs $0.027 \pm 0.029)(p=0.01)$ and the PC/MPV ratio $(24.63 \pm 10.90$ vs $27.63 \pm 10.24)(p=0.001)$, which were simply calculated using these indices, were observed significantly lower than the control group.

\section{Binary Logistic Regression Analysis}

Results of the logistic regression analysis are shown in Table 3. In unadjusted model, increased MPV and BMI, ALT, BUN levels were significantly associated with high odds of having preeclampsia.

\section{Receiver Operating Characteristic (ROC) Curve Analysis}

The ROC curve for MPV for predicting the preeclampsia risk is shown in Figure 1. The area under the ROC curves were 0.634 (95\% Cl 0.587-0.682, p < 0.001) for MPV. The optimal cut-off value of MPV for detecting preeclampsia was $\geq 9.15 \mathrm{ng} / \mathrm{mL}$, at which the sensitivity is $58.7 \%$ and specificity is $61.7 \%$.

\section{DISCUSSION}

There are two consecutive steps in the pathogenesis of preeclampsia. In the first step, utero-placental arterial blood flow decreases and hypoxia develops due to insufficient invasion of cytotrophoblasts to the uterine wall at the maternofetal junction. Released free oxygen radicals cause placental dysfunction, release of anti-angiogenic factors of proinflammatory cytokines, and activation of neutrophils $[9,10]$. In the second step, activated neutrophils infiltrate maternal vascular tissue and PE starts; platelet activation, vasoconstriction, endothelial dysfunction and end-organ ischemia occur [11]. As a result of all this; PE is clinically presented with hypertension, proteinuria, edema, headache, coagulopathy, renal and hepatic dysfunction $[9,12]$.

Table 3. Evaluation of the association between of MPV and age, BMI, ALT,BUN in the study population (women with and without preeclampsia) using the Binary logistic regression analysis

\begin{tabular}{|c|c|c|c|c|}
\hline & \multirow{2}{*}{ OR } & \multicolumn{2}{|l|}{$95 \% \mathrm{Cl}$} & \multirow{2}{*}{$\mathbf{p}$} \\
\hline & & lower & upper & \\
\hline \multicolumn{5}{|c|}{ Variables } \\
\hline Age & 1.046 & 1.011 & 1.083 & 0.009 \\
\hline BMI & 1.140 & 1.091 & 1.191 & $<0.001$ \\
\hline MPV & 1.494 & 1.275 & 1.751 & $<0.001$ \\
\hline ALT & 1.074 & 1.040 & 1.108 & $<0.001$ \\
\hline BUN & 1.275 & 1.183 & 1.374 & $<0.001$ \\
\hline
\end{tabular}

$\mathrm{OR}$ - odds ratio; $\mathrm{Cl}$ - confidence interval; a $\mathrm{p}$ value of $<0.05$ was considered significant $\left(^{*}\right)$
MPV is being studied with increasing interest as a potential marker for the prediction of preeclampsia, since it is easily detectable during complete blood count and reflects indirect platelet reactivity. In our study, MPV value was significantly higher in preeclamptic pregnants in the third trimester compared to normotensive pregnants. There are many studies showing that MPV value increases especially in the 2nd and 3rd trimesters in preeclampsia [11, 13-20].

These studies suggest that disruption of the microcirculation in the cascade beginning with endothelial damage in preeclampsia leads to microtrombus formation, and that platelet count decreases with increasing platelet destruction, and the increase in MPV values of younger and larger platelets as a result of stimulation of platelet production in the bone marrow reflects the increase in MPV values. However, in our study; similar to the results of the study in which Dündar and et al. [21], evaluated the platelet parameters longitudinally in preeclamptic and normotensive pregnancies during the course of pregnancy, an increase in MPV was observed without a decrease in platelet count. In preeclamptic pregnants; while the number of platelets does not change, the number of studies advocating an increase in MPV is not small $[22,23]$. MPV was found to be high in many cases with vascular risk such as diabetes mellitus, hypercholesterolemia, and acute myocardial infarction that did not associated with thrombocytopenia [24]. In preeclampsia,

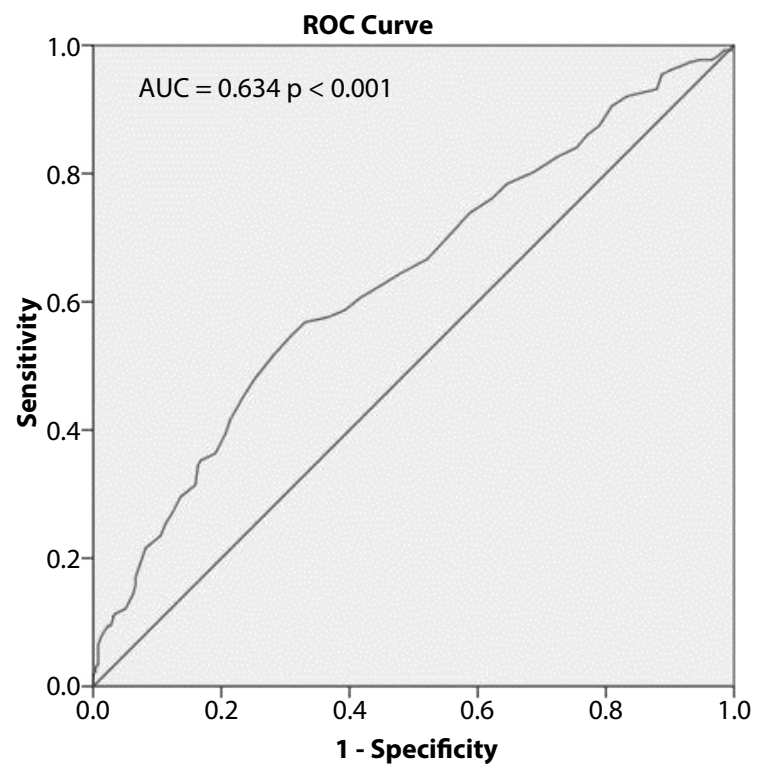

Figure 1. Receiver operating characteristic (ROC) curve for MPV for the prediction of preeclampsia. The estimate of the area under the ROC curve and its $95 \%$ confidence interval is shown. Cut-off value of MPV was $\geq 9.15$ (sensitivity $58.7 \%$ and specificity $61.7 \%$ ) for prediction of preeclampsia. AUC, area under curve. A p value of $<0.05$ was considered significant $\left(^{*}\right)$ 
the interaction between damaged endothelial cells and platelets may disrupt the coagulation process, or large and enzymatically active platelets may have a different role in the pathogenesis of preeclampsia.

To date, the results of studies examining the relationship between preeclampsia and MPV value are conflicting. In addition to numerous studies saying that MPV increases in preeclampsia, there are studies reporting that MPV value decreases [25] or MPV value does not change, and there is no predictive value $[5,26]$. Although these differences are related to the analysis method used, the anticoagulant used, the time taken for analysis, factors such as study design and number of patients included may also be effective [7].

In our study, the optimum cut-off value of MPV for preeclampsia prediction was found to be $\geq 9.15$ with $58.7 \%$ sensitivity and $61.7 \%$ specificity (area under the ROC curve 0.634 , $\mathrm{p}<0.001,95 \%$ Confidence Interval). This value is indicated by Manneerts and his colleagues (16) as 8.15. In the literature, the cut-off values calculated for MPV in preeclampsia prediction ranged between 8.65 and 9.95. [27, 28]

Studies emphasize that platelet indices should not be ignored when evaluating complete blood count. Doğan et al., reported that the risk of developing PE increased by two-fold in patients with platelet counts $\leq 190 * 10^{9} / \mathrm{L}$, two-fold in patients with $M P V \geq 9 \mathrm{fL}$, and 2.4 fold in patients with $P C / M P V$ ratio $\leq 19.9$, but stated that changes in platelet indices were not associated with PE severity [17]. AISheeha et al. [25], reported that in preeclamptic pregnants, platelet count decreased while MPV did not change. In our study, on the contrary, platelet count did not decrease significantly in PE, whereas MPV was found to be significantly higher and ironically, both studies concluded that PC/MPV ratio decreased significantly in preeclampsia.

In our study, the birth weeks of preeclamptic pregnant women, birth weight of infants, and APGAR scores of 1 and 5 minutes were significantly lower. PE is associated with preterm birth and low birth weight [27, 29]. Early recognition should be a primary goal for the prevention of preeclampsia. However, some studies reported that the first trimester MPV value and a meta-analysis showed that the first and second trimester MPV values were not significant in PE prediction [21, 31].

With the MPV value to be evaluated in the third trimester, the follow-up of the pregnants who are predicted to develop PE can be increased and the progression of severe preeclampsia, eclampsia and HELLP with high morbidity and mortality can be reduced and neonatal care conditions can be ensured. The limitations of this study were its retrospective design and non-longitudinal aspect.

\section{CONCLUSIONS}

In our study, MPV, one of the parameters of complete blood count, which can be evaluated as easy, fast and inexpensive in every hospital, was found to be increased in preeclampsia. In prenatal follow-up, evaluating MPV value and PC/MPV ratio may be useful in the prediction of preeclampsia.

Prospective, multicenter, large-scale studies are needed to understand the role of platelets in preeclampsia and to reduce maternal and fetal complications.

\section{Conflict of Interest}

The authors declare that there are no conflicts of interest

\section{Acknowledgements}

All the authors have approved the manuscript and declare no conflicts of interest. This study did not receive any specific grant from any funding agency in the public, commercial or not-for-profit sector.

\section{REFERENCES}

1. Williams ML. Long-term hospitalization of women with high-risk pregnancies. A nurse's viewpoint. J Obstet Gynecol Neonatal Nurs. 1986; 15(1): 17-21, doi: 10.1111/j.1552-6909.1986.tb01362.x, indexed in Pubmed: 3632996.

2. Young B, Levine R, Karumanchi S. Pathogenesis of Preeclampsia. Annual Review of Pathology: Mechanisms of Disease. 2010; 5(1): 173-192, doi: 10.1146/annurev-pathol-121808-102149.

3. Romero R, Lockwood C, Oyarzun E, et al. Toxemia: new concepts in an old disease. Semin Perinatol. ; 12: 302-323.

4. Tygart SG, McRoyan DK, Spinnato JA, et al. Longitudinal study of platelet indices during normal pregnancy. Am J Obstet Gynecol. 1986; 154(4): 883 887, doi: 10.1016/0002-9378(86)90476-x, indexed in Pubmed: 3963077.

5. Ceyhan T, Beyan C, Başer I, et al. The effect of pre-eclampsia on complete blood count, platelet count and mean platelet volume. Ann Hematol. 2006; 85: 320

6. Stubbs TM, Lazarchick J, Van Dorsten JP, et al. Evidence of accelerated platelet production and consumption in nonthrombocytopenic preeclampsia. Am J Obstet Gynecol. 1986; 155(2): 263-265, doi: 10.1016/00029378(86)90803-3, indexed in Pubmed: 3740135.

7. Kanat-Pektas $M$, Yesildager $U$, Tuncer $N$, et al. Could mean platelet volume in late first trimester of pregnancy predict intrauterine growth restriction and pre-eclampsia? J Obstet Gynaecol Res. 2014; 40(7): 1840-1845, doi: 10.1111/jog. 12433, indexed in Pubmed: 25056460.

8. ACOG Practice Bulletin No. 33: Diagnosis and Management of Preeclampsia and Eclampsia. Obstetrics \& Gynecology. 2002; 99(1): 159-167, doi: 10.1097/00006250-200201000-00028.

9. Steegers E, Dadelszen Pv, Duvekot J, et al. Pre-eclampsia. The Lancet 2010; 376(9741): 631-644, doi: 10.1016/s0140-6736(10)60279-6.

10. Saftlas AF, Beydoun $H$, Triche E. Immunogenetic determinants of preeclampsia and related pregnancy disorders: a systematic review. Obstet Gynecol. 2005; 106(1): 162-172, doi: 10.1097/01. AOG.0000167389.97019.37, indexed in Pubmed: 15994633.

11. Yucel B, Ustun B. Neutrophil to lymphocyte ratio, platelet to lymphocyte ratio, mean platelet volume, red cell distribution width and plateletcrit in preeclampsia. Pregnancy Hypertens. 2017; 7: 29-32.

12. Laresgoiti-Servitje E, Gómez-López N, Olson DM. An immunological in sight into the origins of pre-eclampsia. Hum Reprod Update. 2010; 16(5): 510-524, doi: 10.1093/humupd/dmq007, indexed in Pubmed: 20388637.

13. Hutt R, Ogunniyi SO, Sullivan MH, et al. Increased platelet volume and aggregation precede the onset of preeclampsia. Obstet Gynecol. 1994; 83(1): 146-149, indexed in Pubmed: 8272297. 
14. Kurtoglu E, Kokcu A, Celik H, et al. Validity of platelet indices in predicting the risk of developing preeclampsia. J Exp Clin Med. 2016; 33(2): 57-61.

15. Yang SW, Cho $\mathrm{SH}$, Kwon HS, et al. Significance of the platelet distribution width as a severity marker for the development of preeclampsia. Eur J Obstet Gynecol Reprod Biol. 2014; 175: 107-111, doi: 10.1016/j. ejogrb.2013.12.036, indexed in Pubmed: 24502873.

16. Mannaerts D, Heyvaert S, De Cordt C, et al. Are neutrophil/lymphocyte ratio (NLR), platelet/lymphocyte ratio (PLR), and/or mean platelet volume (MPV) clinically useful as predictive parameters for preeclampsia? J Matern Fetal Neonatal Med. 2019; 32(9): 1412-1419, doi: 10.1080/14767058.2017.1410701, indexed in Pubmed: 29179639.

17. Doğan K, Guraslan H, Senturk MB, et al. Can Platelet Count and Platelet Indices Predict the Risk and the Prognosis of Preeclampsia? Hypertens Pregnancy. 2015; 34(4): 434-442, doi: 10.3109/10641955.2015.1060244, indexed in Pubmed: 26362129.

18. Han L, Liu X, Li H, et al. Blood coagulation parameters and platelet indices: changes in normal and preeclamptic pregnancies and predictive values for preeclampsia. PLoS One. 2014; 9(12): e114488, doi: 10.1371/journal. pone.0114488, indexed in Pubmed: 25464515.

19. Freitas LG, Alpoim PN, Komatsuzaki F, et al. Preeclampsia: are platelet count and indices useful for its prognostic? Hematology. 2013; 18(6): 360-364, doi: 10.1179/1607845413Y.0000000098, indexed in Pubmed: 23676885.

20. Moraes D, Munhoz TP, Pinheiro da Costa BE, et al. Immature platelet fraction in hypertensive pregnancy. Platelets. 2016; 27(4): 333-337, doi: 10.3109/09537104.2015.1101060, indexed in Pubmed: 26587995.

21. Dundar $O$, Yoruk $P$, Tutuncu $L$, et al. Longitudinal study of platelet size changes in gestation and predictive power of elevated MPV in development of pre-eclampsia. Prenat Diagn. 2008; 28(11): 1052-1056, doi: 10.1002/pd.2126, indexed in Pubmed: 18973157.
22. Sezer $\mathrm{S}$, Küçük $M$, Yüksel $H$, et al. Preeklamptik gebelerde trombosit parametreleri. Pam Tıp Derg. 2011; 4(2): 66-71.

23. Makuyana D, Mahomed K, Shukusho FD, et al. Liver and kidney function tests in normal and pre-eclamptic gestation--a comparison with non-gestational reference values. Cent Afr J Med. 2002; 48(5-6): 55-59, indexed in Pubmed: 12971159.

24. Bath P, Butterworth RJ. Platelet size. Blood Coagulation \& Fibrinolysis. 1996; 7(2): 157-161, doi: 10.1097/00001721-199603000-00011.

25. AlSheeha MA, Alaboudi RS, Alghasham MA, et al. Platelet count and platelet indices in women with preeclampsia. Vasc Health Risk Manag. 2016; 12: 477-480, doi: 10.2147/VHRM.S120944, indexed in Pubmed: 27920548.

26. Saleh AA, Bottoms SF, Farag AM, et al. Markers for endothelial injury, clotting and platelet activation in preeclampsia. Arch Gynecol Obstet. 1992; 251(3): 105-110, doi: 10.1007/BF02718370, indexed in Pubmed: 1605673.

27. Mouna K, Doddagowda SM, Junjegowda K, et al. Changes in Haematological Parameters in Newborns Born to Preeclamptic Mothers - A Case Control Study in a Rural Hospital. J Clin Diagn Res. 2017; 11(7): EC26-EC29, doi: 10.7860/JCDR/2017/29137.10303, indexed in Pubmed: 28892906.

28. Jacquemyn $Y$, Zemtsova O. Risk factors and prediction of preeclampsia. Acta Clin Belg. 2010; 65(1): 1-12, doi: 10.1179/acb.2010.001, indexed in Pubmed: 20373592.

29. Zupan-Simunek V. [Prognosis in newborns after mother's preeclampsia]. Ann Fr Anesth Reanim. 2010; 29(5): e135-e139, doi: 10.1016/j. annfar.2010.03.013, indexed in Pubmed: 20478688.

30. Bellos I, Fitrou G, Pergialiotis V, et al. Mean platelet volume values in preeclampsia: A systematic review and meta-analysis. Pregnancy Hypertens. 2018; 13: 174-180, doi: 10.1016/j.preghy.2018.06.016, indexed in Pubmed: 30177049. 